\title{
WHEN CARDIOVASCULAR COMPLICATIONS OCCUR IN YOUNG PATIENTS WITH TYPE 1 DIABETES MELLITUS AND HOW SHOULD WE DEMONSTRATE IT?
}

\author{
Mehmet Eyuboglu
}

Dear Editor,

In a recent issue of your journal, I have read the article by Bućan et al. with great interest ${ }^{1}$. In their study, the authors report that there was no statistically significant correlation between the duration of type 1 diabetes mellitus (DM) and echocardiographic values. It is known that DM increases the prevalence of cardiovascular diseases (CVD) independently of the underlying coronary artery disease ${ }^{2}$. In the present study by Bućan et al., the mean age of study population was 33 years, and 43.5 years for the oldest group. In a large study that included 3200 patients with type $1 \mathrm{DM}$, the prevalence of CVD was found to be $6 \%$ in the 15-29 age group and $25 \%$ in the $45-59$ age group. The prevalence of CVD was related to the increase in age significantly ${ }^{3}$. Therefore, this study population may be younger for cardiovascular complications of type $1 \mathrm{DM}$.

The relationship of hyperglycemia with microangiopathy as well as macroangiopathy is more significant in type $1 \mathrm{DM}$ than type $2 \mathrm{DM}^{4}$. In the present study by Bućan et al., HbA1c levels were $<9 \%$. Also, patients with hypertension and other heart and kidney diseases were excluded. In this sense, this study population may have a low risk of CVD, especially of systolic dysfunction, which can be a complication of microangiopathy and macroangiopathy.

In a large study which included type $1 \mathrm{DM}$ patients diagnosed at the age of $<18$ years between 1965 and

Correspondence to: Mehmet Eyuboglu, MD, Department of Cardiology, Dinar State Hospital, Dinar, Afyonkarahisar, Turkey 03400 E-mail:mhmtybgl@gmail.com

Received May 19, 2015, accepted January 8, 2016

Letter to the Editor about the article: Left ventricular systolic function in selected type 1 diabetic patients with or without diabetic retinopathy and microalbuminuria. Acta Clin Croat 2014;53: 383-389.
1979, CVD was identified as the leading cause of death in diabetes after more than 20 years of duration. In the first 20 years of follow up, the major reasons for complications were acute diabetic complications and endstage renal disease ${ }^{5}$. Also, in the Finnish Diabetic Nephropathy study ${ }^{6}$, excess mortality was only observed in individuals with chronic kidney disease in type $1 \mathrm{DM}$ patients with diabetes duration of over 20 years. This finding suggests that kidney damage in individuals with type $1 \mathrm{DM}$ reflects more generalized damage to the cardiovascular system leading to CVD and subsequently to mortality. In the present study by Bućan et al., the mean duration of DM was 11 years and longest duration of DM was 17.1 years. Hence, these durations may be short times to have effect on systolic function and cardiovascular damage in type $1 \mathrm{DM}$ patients. A longer follow up period may indicate new findings.

It is known that diastolic dysfunction appears before systolic dysfunction in CVD. Also, impaired left ventricle systolic function has been demonstrated by tissue doppler imaging while ejection fraction is in the normal range $^{7}$. Therefore, to evaluate the cardiovascular effect of DM by ejection fraction only may be a wrong approach. It may cause to miss the early phase of CVD.

In conclusion, the analysis of this study may be improved. This study included younger patients, short duration of DM and ejection fraction as echocardiographic parameter. Longer follow up and using more sensitive echocardiographic parameters such as tissue doppler imaging may have effect on the results of this study.

\section{References}

1. Bućan K, Bojić L, Fabijanić D, Galetović D, Čapkun V, Utrobičić DK, et al. Left ventricular systolic function in selected type 1 diabetic patients with or without diabetic retinopathy and microalbuminuria. Acta Clin Croat. 2014;53:383-9. 
2. Boudina S, Abel ED. Diabetic cardiomyopathy revisited. Circulation. 2007;115:3213-23.

3. Koivisto VA, Stevens LK, Mattock M, Ebeling P, Muggeo M, Stephenson J, et al;; EURODIAB IDDM Complications Study Group. Cardiovascular disease and its risk factors in IDDM in Europe. Diabetes Care. 1996;19:689-97.

4. Juutilainen A, Lehto S, Ronnemaa T, Pyorala K, Laakso M. Similarity of the impact of type 1 and type 2 diabetes on cardiovascular mortality in middle-aged subjects. Diabetes Care. 2008;31:714-9.

5. Morimoto A, Onda Y, Nishimura R, Sano H, Utsunomiya K, Tajima N; Diabetes Epidemiology Research International
Mortality Study Group. Cause-specific mortality trends in a nationwide population-based cohort of childhood-onset type 1 diabetes in Japan during 35 years of follow-up: the DERI Mortality Study. Diabetologia. 2013;56:2171-5.

6. Groop PH, Thomas MC, Moran JL, Wadèn J, Thorn LM, Mäkinen VP, et al.; FinnDiane Study Group. The presence and severity of chronic kidney disease predicts all-cause mortality in type 1 diabetes. Diabetes. 2009;58:1651-8.

7. Yu CM, Lin H, Yang H, Kong SL, Zhang Q, Lee SW. Progression of systolic abnormalities in patients with "isolated" diastolic heart failure and diastolic dysfunction. Circulation. 2002;105:1195-201. 